\title{
PELAYARAN HAJI ORANG MELAYU SEBELUM PERANG DUNIA KEDUA
}

\author{
Aiza Maslan @ Baharudin
}

\begin{abstract}
The pilgrimage of Malays to Mecca, the Holy Land is always rife with problems from the transportation aspects, especially the issue of crowded ships. Between the years 1870 to 1872, ships carrying hajj pilgrims from the port of Singapore were reportedly carrying passengers exceeding the legal capacity as provided by the law. Local Malay language newspapers often featured the thoughts and feelings of Malays who considered the state of the crowded and dirty ships carrying the pilgrims as an insult to their dignity, religion and race. Although many complaints were voiced by various parties, congestion on the hajj ships was still a major problem in the pilgrimage until the 1950's. The ships' conditions; crowded with pilgrims and cargo were caused by those who wanted to take advantage of the Muslim pilgrimage. The incident that happened to the ship S. S. Jeddah that almost sunk with a thousand pilgrims on board had smeared the transportation industry, thereby embarrassing the British who had been overseeing all the affairs in respect of pilgrims' transportation.
\end{abstract}

\section{Pengenalan}

Menurut sejarah, perjalanan orang Melayu untuk menunaikan ibadah haji bukanlah suatu perkara yang mudah dan selamat. Pelayaran haji pada zaman awal sering dikaitkan dengan perjalanan terakhir dalam kalangan orang Melayu berikutan keadaan kesukaran dan kepayahan yang harus dilalui oleh jemaah haji. Antara cabaran dan rintangan yang harus diharungi oleh jemaah haji adalah keadaan pelayaran yang memakan masa yang terlalu lama dan mereka sering terdedah kepada 
pelbagai bentuk bahaya, seperti dipukul ribut dan diserang wabak penyakit.

Sebelum penggunaan kapal wap, jemaah haji dari Tanah Melayu menggunakan kapal layar untuk ke Tanah Suci Mekah yang memakan masa berbulan-bulan lamanya kerana terpaksa bergantung kepada kadar tiupan angin. Pembukaan Terusan Suez dan pengenalan kapal wap secara tidak langsung telah merubah corak pelayaran haji orang Melayu. Walaupun tempoh pelayaran ke Tanah Suci Mekah berjaya disingkatkan, pelayaran haji orang Melayu masih tidak sunyi daripada belenggu masalah, terutamanya yang berkaitan dengan kesesakan penumpang di dalam kapal. Pelbagai pihak pernah tampil menyuarakan masalah berhubung kesesakan tersebut melalui saluran yang pelbagai termasuklah melalui surat-menyurat rasmi, catatan memoir dan tulisan dalam akhbar tempatan.

\section{Orang Melayu dan Pelayaran Haji}

Menurut kajian yang dilakukan oleh Roff, pelayaran jemaah haji Melayu pada zaman awal ke Tanah Suci dibuat dengan menumpang kapal-kapal dagang, iaitu kapal-kapal layar yang kecil seberat antara 100 hingga 300 tan milik orang perseorangan dari pelbagai negara. ${ }^{1}$ Pada kebiasaannya jemaah haji Tanah Melayu akan singgah di Aceh bagi menanti kapal dagang untuk ditumpang ke pelabuhan seterusnya. Selama beberapa abad lamanya, Aceh telah bertindak sebagai pusat perdagangan rempah-ratus dan pengajian ilmu-ilmu Islam kerana sering dikunjungi oleh pedagang-pedagang Arab dan Parsi. ${ }^{2}$ Sesuai dengan peranannya sebagai sebuah pelabuhan penghubung di antara pelabuhan Asia Tenggara dan Timur Tengah, Aceh secara tidak langsung telah bertindak sebagai pelabuhan haji bagi jemaah haji Melayu yang ingin ke Tanah Suci Mekah. ${ }^{3}$

...we must remember that before sailing ships were replaced by steamers as a means of conveyance for visitants to Mekka, Acheh formed a great halting-place for almost all the pilgrims from the Eastern Archipelago. The Achehnese used to speak of their country with some pride as "the gate of the Holy Land. ${ }^{4}$

Sebelum pendudukan British di Pulau Pinang pada tahun 1786, pedagang Arab ${ }^{5}$ dan India Muslim atau Culia ${ }^{6}$ dari Pantai Koromandel telah pun menjalankan perdagangan dengan Aceh dan beberapa buah pelabuhan kecil di Sumatera Barat dan Sumatera Timur, terutamanya selepas kejatuhan Kerajaan Melaka ke tangan Portugis. Barangan dagangan utama yang dibawa oleh pedagang-pedagang Culia untuk 
dipasarkan di Kepulauan Melayu ialah kain tenunan India, candu dan garam. Kapal-kapal mereka yang merentasi Lautan Hindi akan singgah di pelabuhan Aceh, Pedir dan Sawang bagi mendapatkan bekalan lada hitam dan pinang. Aceh juga merupakan pengedar utama kain-kain kapas India di Kepulauan Melayu sebelum kemunculan Pulau Pinang. Di samping komoditi perdagangan, kapal-kapal dagang ini turut membawa bakal haji dari Kepulauan Melayu, sepertimana peranan yang dimainkan oleh kapal dagang dari Parsi. Sebanyak empat hingga lima buah kapal besar milik orang Arab dari Jeddah, Surat dan pelabuhanpelabuhan lain singgah di Aceh pada setiap tahun, menumpangkan jemaah haji Melayu yang ingin pulang ke tanah air dan membawa yang lain ke Mekah sehingga jumlah mereka mencecah angka 1,000 orang pada setiap tahun. ${ }^{7}$

Formerly the Malays must trust themselves to Arab sailing captains who overcrowded their ships at Acheh (Acheen), Singapore etc., and did not regard it as an unmixed evil if during the voyage the mass of passengers was somewhat thinned out by epidemics etc. ${ }^{8}$

Kapal-kapal orang Arab ini akan membawa jemaah haji Melayu ke Hadramaut, Yaman atau terus ke Jeddah. ${ }^{9}$ Walaupun jemaah haji Melayu terpaksa bersesak-sesak di atas kapal dengan berbondongbondong bungkusan dan barangan di sekeliling mereka, namun peluang ini tidak dilepaskan kerana kesempatan tersebut membolehkan mereka menunaikan ibadah haji. Perjalanan ini kadang kala berlanjutan sehingga setengah tahun atau mungkin lebih bergantung kepada keadaan tiupan angin. Setelah selesai menunaikan fardu haji, jemaah haji akan menumpang kapal-kapal ke Yaman atau Hadramaut untuk menanti kapal-kapal dagang dari India yang akan membawa mereka kembali ke Aceh. ${ }^{10}$

Pembukaan Terusan Suez telah menggalakkan industri perkapalan dan mempercepatkan perkhidmatan kapal wap ke Asia. Abdullah Munsyi mencatatkan bahawa kapal wap pertama berlabuh di Pelabuhan Singapura ialah P. S. Sesostris pada 3 Ogos $1841 .{ }^{11}$ Faktor ini secara tidak langsung melenyapkan penggunaan kapal layar secara beransuransur, sekali gus membuka peluang kepada syarikat perkapalan Eropah bersaing untuk mengaut keuntungan besar melalui pengangkutan jemaah haji Melayu dan Indonesia ke Tanah Suci Mekah. ${ }^{12}$ Menurut Rutter, menjelang akhir abad ke-19, syarikat perkapalan mula menyedari bahawa pengangkutan laut membawa jemaah haji pergi dan balik dari Tanah Suci Mekah merupakan satu perniagaan yang amat menguntungkan kerana mereka boleh memanfaatkan setiap ruangan kapal yang ada. Ruangan atas dan dek kapal boleh diisi dengan jemaah 
haji, sementara bahagian bawahnya dimuatkan dengan barangan dagangan dan keperluan, seperti beras, gula, kopi, kayu balak dan lain-lain untuk dijual di Jeddah. Syarikat-syarikat perkapalan British, Belanda, Peranchis, Itali, Rusia, Greek dan Jerman tumbuh bagai cendawan selepas hujan yang menawarkan pengangkutan pergi balik secara berjadual atau sewa khas. ${ }^{13}$

Antara syarikat perkapalan yang cukup sinonim dengan pengangkutan haji dalam kalangan orang Melayu ialah The Ocean Steam Ship Company Limited atau The Blue Funnel Line yang ditubuhkan oleh Alfred dan Philip Holt pada tahun 1865. Syarikat The Blue Funnel telah memulakan perdagangan pengangkutan jemaah haji yang lebih kerap dan tetap antara Negeri-Negeri Selat dan Jeddah dalam tahun 1875. Menurut laporan yang dibuat oleh Konsul British di Jeddah, sebelum tahun 1928 sebanyak 85 peratus jemaah haji Tanah Melayu menggunakan perkhidmatan kapal syarikat berkenaan. ${ }^{14}$

Dua buah syarikat lain yang turut menawarkan perkhidmatan pengangkutan haji ialah Syarikat The Ocean Navigation Company of Hongkong ${ }^{15}$ dan The Straits-Hejaz Company. ${ }^{16}$ Walau bagaimanapun, mulai tahun 1928, kedua-dua buah syarikat berkenaan tidak lagi dipertanggungjawabkan membawa jemaah haji kerana pengurusan pihak syarikat yang tidak efisyen dan sering menimbulkan kesulitan kepada jemaah haji. Kedua-dua buah syarikat dilaporkan sering gagal membawa pulang jemaah haji dari Jeddah dalam tempoh 20 hari yang ditetapkan. Selain kelemahan pentadbirannya di Hong Kong dan India, kapal Syarikat The Ocean Navigation Company of Hongkong juga dilaporkan kecil dan kotor. Satu-satunya kes kolera yang dilaporkan berlaku dalam tahun 1926 yang melibatkan kapal haji adalah di atas kapal syarikat berkenaan. Syarikat tersebut juga gagal menyediakan kemudahan doktor di dalam pelayaran sebanyak dua kali dalam tempoh tiga tahun. Satu lagi bentuk eksploitasi yang sering dilakukan oleh pihak pengurusan syarikat kapal berkenaan ialah memberikan keutamaan kepada pembeli tiket sehala di Jeddah dan mengetepikan pemegang tiket pergi balik, terutama bagi kelas satu dan dua. Pada musim haji tahun 1926, seramai 870 orang jemaah haji Tanah Melayu yang menggunakan perkhidmatan syarikat berkenaan terkandas di Jeddah selama 42 hari. $^{17}$

\section{Kesesakan Kapal Haji}

Walaupun pengenalan kapal wap merupakan satu pencapaian besar dalam industri pengangkutan memandangkan tempoh pelayaran dari Tanah Melayu ke Tanah Suci Mekah berjaya dipendekkan dari dua hingga tiga bulan kepada tiga minggu sahaja, pelbagai masalah masih 
mengganggu proses pemergian jemaah haji ke Tanah Suci, terutamanya melibatkan masalah kesesakan di atas kapal. Kesesakan kapal haji bukan merupakan isu baru dalam industri haji. Tulisan Abdullah Munsyi umpamanya, Kisah Pelayaran Abdullah ka-Judah antara lain menggambarkan keadaan kesesakan di atas kapal haji dan kepayahan yang terpaksa diharungi oleh jemaah haji pada zaman penggunaan kapal layar. Kapal yang terlalu padat dan sesak bukan sahaja dengan penumpang, tetapi juga dengan muatan dagangan seperti beras menyebabkan keadaan yang terlalu panas dan tidak selesa di dalam kapal. Ketiadaan sistem pengaliran udara yang sempurna dan masa pelayaran yang memakan masa terlalu lama juga telah menyebabkan berlakunya jangkitan penyakit cacar yang membawa kepada kematian jemaah haji sepanjang pelayaran.

Maka ada-lah dalam kapal dua puloh lebeh orang yang kena penyakit ketumbohan; ada-lah dua tiga orang yang mati. Maka terlebeh ma'lum-lah tuan2 yang menengarkan hikayat-ku ini, karena terlalu-lah sangat dudok dalam kesusahan pelayaran itu kapada orang yang baik, istimewa pula kapada orang yang berpenyakit. Yang dalam demikian itu ada juga orang yang di-beri Allah dengan selamat-nya, segera-lah semboh, ada orang yang sangat berat sebab dudok dalam susah dan panas; maka tambahan pula kapal itu bermuat beras, panasnya siang malam saperti di-atas api, ada-nya. ${ }^{18}$

Catatan ringkas oleh Jaafar bin Jusoh, Perihal Pemergian ke Mekah dan Madinah yang mengisahkan pengalaman menunaikan ibadah haji pada tahun 1936 turut memperihalkan kesusahan yang terpaksa ditempuhi oleh jemaah haji sepanjang pelayaran menuju ke Jeddah. Para penumpang yang ditempatkan di perut kapal terpaksa duduk dalam kepanasan dan kesesakan akibat berhimpit dengan barang-barang dan muatan yang berlebihan dalam pelayaran yang memakan masa berpuluh-puluh hari. ${ }^{19}$ Perkara ini sekali lagi dibangkitkan oleh Jaafar dalam tulisan beliau semasa menggambarkan pelayaran pulang jemaah haji ke tanah air, sekali gus memberikan isyarat bahawa kesesakan yang dialami oleh jemaah haji sepanjang pelayaran pergi dan pulang daripada mengerjakan ibadah haji bukanlah masalah yang remeh sebaliknya perlu diberi perhatian serius oleh pelbagai pihak.$^{20}$

Sepanjang tempoh 50 tahun, iaitu dari tahun 1860 - 1909, masih terdapat kesesakan yang begitu serius dilaporkan di atas kapal yang membawa jemaah haji. Kebimbangan terhadap kehilangan barangbarang memaksa jemaah haji menempatkan segala barangan yang dibawa di sekeliling tempat berehat dan tidur. Perbuatan tersebut telah menyebabkan keadaan kapal yang membawa jemaah haji melebihi had muatan yang sepatutnya menjadi semakin sesak. Jemaah haji 
terpaksa duduk berasak-asak dan berhimpit dengan muatan kargo dan barangan yang dibawa sehingga sukar mencari ruangan untuk berdiri. Masalah kesesakan kapal haji merupakan salah satu isu yang akhirnya telah mendorong campur tangan pihak British dalam urusan haji orang Melayu. ${ }^{21}$

Forty years ago the pilgrimage to Mecca was a costly and hazardous venture. The sufferings that pilgrims for months had to undergo on ill-found, overcrowded, and insanitary sailing ships, and the dangers to which they were exposed on the overland journey from Jedah to Mecca and back, were such that only fervent Muhammadans would face, and few Malays are such. Not many had the means to undertake a journey which would take the best part of a year to perform, as well as to satisfy the insatiable extortions to which they were subjected from the moment they set their feet in Arabia. Now, the welfare of the Muhammadan pilgrim is so well safeguarded by Christian ordinances...22

Surat-menyurat rasmi di antara Singapura dan Bengal pada tahun 1849, antara lain menyentuh tentang jumlah kematian seramai 83 orang dalam pelayaran sebuah kapal seberat 290 tan yang membawa 520 orang jemaah haji dari Jeddah ke Singapura. Walau bagaimanapun, tiada sebarang tindakan tegas dikenakan terhadap pemilik kapal berkenaan. ${ }^{23}$ Keadaan kesesakan dalam kapal yang membawa jemaah haji turut disuarakan oleh Gabenor Negeri-Negeri Selat, Harry Ord (1867-1873) kepada Pejabat Tanah Jajahan, London pada tahun 1869 yang mengemukakan persoalan terhadap kejadian sebuah kapal wap, iaitu S. S. Dream yang belayar dari Singapura dengan membawa 300 peratus muatan melebih had yang sepatutnya. Kapal berkenaan membawa bersamanya 223 orang jemaah, melebihi kadar yang ditetapkan, iaitu 216 orang. Kesesakan yang semakin serius berlaku apabila kapal tersebut mengambil tambahan penumpang seramai 393 orang jemaah haji di pelabuhan-pelabuhan di Sumatera sehingga menyebabkan kesukaran kepada penumpang untuk bergerak dan berbaring. ${ }^{24}$

Antara Oktober 1870 sehingga Disember 1872, tujuh daripada 29 buah kapal milik British yang disenaraikan membawa jemaah haji, meninggalkan Singapura dengan jumlah penumpang melebihi muatan yang diperuntukkan undang-undang. Kapal Venus, seberat 928 tan meninggalkan Singapura pada September 1871 bersama 1,200 orang, iaitu 582 orang melebihi kadar sepatutnya. Manakala, kapal Sinfoo, seberat 918 tan yang berlepas pada September 1872, membawa 1,000 orang, iaitu 268 penumpang melebihi had yang dibenarkan. Perbuatan tersebut telah melanggar The Indian Law No. 21, 1858 dan The Straits Ordinance No. 6, 1870 yang mensyaratkan ' 9 superficial and 54 cubial feet in the between decks and 4 superficial feet on the upper deck shall be allowed to 
each adult passenger (counting each passenger above 12 and 2 children between 1 and 12 years as an adult). Ini bermakna jumlah penumpang termasuk anak-anak kapal adalah bagi setiap tiga tan dinisbahkan kepada seorang penumpang. ${ }^{25}$

JADUAL 1: Senarai kapal dan jumlah jemaah haji yang meninggalkan pelabuhan Singapura pada tahun 1870-1872.

\begin{tabular}{|c|c|c|c|c|c|c|}
\hline TAHUN & TARIKH & BENDERA & NAMA KAPAL & TON & $\begin{array}{c}\text { JUMLAH } \\
\text { PENUMPANG }\end{array}$ & $\begin{array}{c}\text { LEBIHAN } \\
\text { PENUMPANG }\end{array}$ \\
\hline 1870 & $\begin{array}{l}15 \mathrm{Oct} \\
27 \mathrm{Oct} \\
28 \mathrm{Oct} \\
29 \mathrm{Oct} \\
\mathrm{Nov} \\
7 \mathrm{Nov} \\
11 \mathrm{Nov} \\
26 \mathrm{Nov} \\
1 \mathrm{Dec}\end{array}$ & $\begin{array}{l}\text { BRITAIN } \\
\text { BRITAIN } \\
\text { ARAB } \\
\text { ARAB } \\
\text { BRITAIN } \\
\text { BRITAIN } \\
\text { BRITAIN } \\
\text { BRITAIN } \\
\text { DUTCH }\end{array}$ & $\begin{array}{l}\text { ALBATROOS } \\
\text { ALBATROOS } \\
\text { FATTLE WADOOD } \\
\text { FOOLKHOL KHAIR } \\
\text { FATHOOL CARIM } \\
\text { WM CHANDLER } \\
\text { FAIDATHUL ILLAH } \\
\text { SOAD BAN } \\
\text { GRAHAM }\end{array}$ & $\begin{array}{l}661 \\
649 \\
460 \\
895 \\
1212 \\
859 \\
895 \\
411 \\
616\end{array}$ & $\begin{array}{l}50 \\
300 \\
262 \\
549 \\
761 \\
537 \\
555 \\
248 \\
369\end{array}$ & \\
\hline 1871 & $\begin{array}{l}18 \text { Jan } \\
13 \text { Sept } \\
18 \text { Sept } \\
20 \text { Sept } \\
20 \text { Sept } \\
5 \text { Oct } \\
21 \text { Oct } \\
25 \text { Oct } \\
31 \text { Oct } \\
2 \text { Nov } \\
18 \text { Nov } \\
29 \mathrm{Dec}\end{array}$ & $\begin{array}{l}\text { BRITAIN } \\
\text { BRITAIN } \\
\text { BRITAIN } \\
\text { BRITAIN } \\
\text { BRITAIN } \\
\text { BRITAIN } \\
\text { ARAB } \\
\text { ARAB } \\
\text { BRITAIN } \\
\text { BRITAIN } \\
\text { BRITAIN } \\
\text { BRITAIN }\end{array}$ & $\begin{array}{l}\text { ACHILLES } \\
\text { LORNE } \\
\text { VENUS } \\
\text { ATHOLL } \\
\text { MENELAUS } \\
\text { FUSIYAMA } \\
\text { FOOLKHOL KHAIR } \\
\text { FATTLE WADOOD } \\
\text { WM CHANDLER } \\
\text { FATHOOL CARIM } \\
\text { HECTOR } \\
\text { ACHILLES }\end{array}$ & \begin{tabular}{|l}
1550 \\
1034 \\
928 \\
1076 \\
1526 \\
800 \\
895 \\
460 \\
859 \\
1212 \\
1522 \\
1550
\end{tabular} & $\begin{array}{l}480 \\
266 \\
1200 \\
150 \\
700 \\
800 \\
547 \\
262 \\
537 \\
762 \\
800 \\
500\end{array}$ & 582 \\
\hline 1872 & $\begin{array}{l}28 \mathrm{Aug} \\
13 \mathrm{Sept} \\
28 \mathrm{Sept} \\
4 \mathrm{Oct} \\
14 \mathrm{Oct} \\
25 \mathrm{Oct} \\
28 \mathrm{Oct} \\
30 \mathrm{Oct} \\
31 \mathrm{Oct} \\
\text { Nov } \\
15 \mathrm{Nov} \\
16 \mathrm{Nov} \\
19 \mathrm{Nov} \\
5 \mathrm{Dec} \\
17 \mathrm{Dec}\end{array}$ & $\begin{array}{l}\text { BRITAIN } \\
\text { BRITAIN } \\
\text { BRITAIN } \\
\text { BRITAIN } \\
\text { BRITAIN } \\
\text { BRITAIN } \\
\text { BRITAIN } \\
\text { BRITAIN } \\
\text { BRITAIN } \\
\text { BRITAIN } \\
\text { ARAB } \\
\text { ARAB } \\
\text { BRITAIN } \\
\text { BRITAIN } \\
\text { BRITAIN }\end{array}$ & $\begin{array}{l}\text { DEUCALION } \\
\text { SINFOO } \\
\text { ADA } \\
\text { PRIAM } \\
\text { FUSIYAMA } \\
\text { ODESSA } \\
\text { RANGOON } \\
\text { FATHOOL CARIM } \\
\text { WM CHANDLER } \\
\text { HECTOR } \\
\text { NASRUL MAJID } \\
\text { FATHOOL BARRY } \\
\text { JEDDAH } \\
\text { DIOMED } \\
\text { SINFOO }\end{array}$ & $\begin{array}{l}1596 \\
918 \\
795 \\
1572 \\
800 \\
820 \\
353 \\
1212 \\
- \\
1512 \\
667 \\
705 \\
991 \\
1210 \\
918\end{array}$ & $\begin{array}{l}350 \\
1000 \\
798 \\
650 \\
800 \\
- \\
500 \\
762 \\
- \\
500 \\
404 \\
434 \\
1000 \\
200 \\
400\end{array}$ & \begin{tabular}{|l}
388 \\
268 \\
\\
267 \\
265
\end{tabular} \\
\hline
\end{tabular}

Sumber: “Alleged Overcrowding of Pilgrim Ships at Singapore”, 4 July 1873, C0 273/67/8938. 
Peristiwa kapal-kapal British yang berlepas dari Singapura membawa penumpang melebihi kadar yang ditetapkan jelas menunjukkan berlakunya penyelewengan tanggungjawab oleh Master Attendant di Singapura yang dipertanggungjawabkan 'not to give his counter signature to Bonds in these cases until he had satisfied himself that the requirements of the Indian Act had been performed especially that aimed against overcrowding ${ }^{\prime 26}$ Surat-menyurat rasmi antara Konsul British di Jeddah dan Pejabat Tanah Jajahan, London pada tahun 1875 masih menekankan isu yang sama. Kapal-kapal yang membawa jemaah haji dari India dan Negeri-Negeri Selat didapati membawa 300 ke 400 orang penumpang melebihi jumlah yang tercatat di dalam surat kebenaran berlepas. Penetapan bahawa setiap kapal dari India dikehendaki berhenti di Aden bagi tujuan pemantauan terhadap sebarang kegiatan membawa penumpang melebihi muatan jelas tidak menampakkan sebarang kesan positif. Ketika pemeriksaan dijalankan di Aden, jumlah penumpang kapal pada kebiasaannya memenuhi peruntukan yang ditetapkan, sebaliknya ketika kapal berlabuh di Jeddah, didapati berlaku peningkatan terhadap jumlah tersebut. Kemungkinan yang dapat dibuat ialah tambahan penumpang berlaku di beberapa buah pelabuhan lain selepas kapal tersebut meninggalkan Aden, terutamanya di pelabuhan Hodeidah. Kapal-kapal dari Singapura dan Pulau Pinang yang belayar di bawah peruntukan Akta Kerajaan Tanah Jajahan (Colonial Government Act) walau bagaimanapun dikecualikan daripada menjalani sebarang bentuk pemantauan di Aden. ${ }^{27}$

Selain membawajumlah penumpang melebihi had yang sepatutnya, kebajikan jemaah haji juga sering diketepikan sama sekali oleh pemilik kapal. Terdapat jemaah haji yang ditempatkan di ruangan dek terbuka yang mengundang bahaya terjatuh dari kapal dalam keadaan ribut dan ketika kapal dilanda gelombang besar. Tiada sebarang pemantauan dilakukan oleh pemilik kapal terhadap pemasalahan kebersihan, bekalan air minuman dan makanan, kawasan memasak, pengaliran udara, tempat tidur, tandas dan kemudahan perubatan. Sudah menjadi suatu kebiasaan jemaah haji akan jatuh sakit setibanya mereka di Jeddah sebagai akibat daripada keadaan pelayaran yang sangat memeritkan. ${ }^{28}$ Kapten Henry Carter ${ }^{29}$ yang pernah beberapa kali berkhidmat sebagai kapten kapal yang membawa jemaah haji pernah menyifatkan keadaan kapal-kapal tersebut lebih teruk daripada kapal-kapal yang membawa hamba abdi:

For the eighteen or twenty days of the voyage to Jeddah a 1,000 pilgrims were cramped together, with little room to move and little or no fresh air. They slept on the bare decks and, stretching hoarded savings to cover a 
pilgrimage to the Holy Land, subsisted on whatever food they had been foresighted enough, or affluent enough to bring with them. ${ }^{30}$

Bahaya yang terpaksa ditempuhi oleh jemaah haji tetap sama apabila kapal-kapal dari Eropah yang sedang dalam pelayaran menuju ke Timur, singgah di Jeddah untuk mengaut keuntungan daripada pengangkutan haji. Pemilik kapal berkenaan bertindak mengangkut Jemaah haji tanpa mengambil kira keadaan dek kapal yang telah dipenuhi dengan kargo, ketiadaan kelengkapan untuk memasak, kekurangan bekalan makanan dan air yang mencukupi dan ketiadaan tempat berteduh bagi jemaah haji dalam cuaca buruk. Jemaah haji dimuatkan di atas kapal sepadat mungkin tanpa sebarang had. Penyelewengan tersebut dilakukan dengan mendapat kerjasama pegawai-pegawai yang bertugas di pelabuhan dengan memalsukan jumlah penumpang supaya memenuhi kadar yang diperuntukan 'two adults for every three tons of the vessel's Register, exclusive of Crew'. Dalam keadaan tersebut dapat digambarkan kesukaran dan keperitan yang terpaksa ditanggung oleh jemaah haji dalam mengharungi suatu perjalanan yang jauh dan memakan masa yang lama. ${ }^{31}$ Gabenor Negeri-Negeri Selat, William Orfeur Cavenagh (1859-1867) mencatatkan bahawa orang Melayu pernah mengemukakan gambaran tentang penderitaan dan layanan buruk kapten-kapten kapal yang diterima mereka sepanjang pelayaran. ${ }^{32}$ Laporan yang dikemukakan oleh pentadbiran Kolonial Belanda tentang kapal-kapal yang membawa jemaah haji turut mengemukakan perkara yang sama:

Dalam laporan Kolonial dikatakan bahwa kapal yang sarat dengan penumpang ditambah barang-barang calon jamaah sangat banyak sehingga lorong-lorong kapal penuh dengan tumpukan barang yang diletakkan di sepanjang gang yang ada. Akibatnya untuk melaksanakan shalat pun sudah tiada ada tempat. Bahkan yang lebih dahsyat lagi ada penumpang yang hendak membuang hajat kecil dan besar terpaksa dilakukan di tempatnya bernaung. Selama bongkar-muat barang, penumpangnya terpaksa harus mengurus makanan sendiri baik di kapal maupun harus dibawa ke pinggir pelabuhan. Fasilitas tidak memuaskan dan jauh dari pensyaratan kadangkala jamaah harus berhadapan dengan sebagian nakhoda kapal yang memiliki sikap yang kurang simpatik. Ada yang melakukan tindakan kekerasan fisik atau membuang sebagian barang milik jamaah ke laut tanpa ada perlawanan yang dilakukan. Tetapi lain halnya bagi penumpang yang bertubuh tegap, kekar dan berani mempertaruhkan jiwa demi mencapai tujuan untuk menunaikan ibadah haji, kadangkala sampai terjadi pertengkaran yang tidak jarang meningkat menjadi perkelahian. ${ }^{33}$ 
Kesukaran dan keperitan yang terpaksa ditempuhi oleh jemaah haji telah mendorong timbulnya cadangan agar mewajibkan penggunaan pas haji ke atas setiap jemaah haji dengan dikenakan kadar bayaran sebanyak \$1.00 seorang. Sistem tersebut membantu mengenal pasti pelanggaran peraturan jumlah penumpang oleh pihak kapal, sekali gus menjadi panduan sekiranya berlaku sebarang masalah termasuk mengembalikan harta jemaah yang meninggal dunia. ${ }^{34}$ Pemilik atau penyewa kapal bertanggungjawab sepenuhnya bagi memastikan jemaah haji yang menaiki kapal mereka memiliki pas haji sebagai salah satu syarat bagi mendapatkan surat kebenaran berlepas. ${ }^{35}$

\section{Insiden Kapal S. S. Jeddah}

Salah satu insiden yang pernah menggemparkan masyarakat dunia, sekali gus mencacatkan industri pengangkutan haji ialah pengalaman ngeri kapal S. S. Jeddah ${ }^{36}$ yang terkandas di Tanjung Guardafui, pintu masuk Teluk Aden, bersama 1,000 orang bakal haji. ${ }^{37}$ Kapal berkenaan meninggalkan Singapura pada 17 Julai 1880 menuju ke Pulau Pinang untuk mengambil bakal haji bagi meneruskan pelayaran ke Tanah Suci Mekah. ${ }^{38}$ Walaupun laporan asal merekodkan jumlah penumpang dewasa adalah seramai 953 orang, tetapi laporan dari Aden menunjukkan ketika ditunda memasuki Pelabuhan Aden, S. S. Jeddah membawa 992 orang penumpang, 778 lelaki, 147 wanita dan 67 kanak-kanak. Kapal seberat 993 tan bersama 992 penumpang dan 50 anak kapal adalah jelas melebihi muatan yang ditetapkan. ${ }^{39}$

Setelah 18 hari pelayaran meninggalkan Pulau Pinang pada 20 Julai 1880, jemaah haji terpaksa berhadapan dengan perubahan cuaca yang tidak menentu. Keadaan ini akhirnya telah merosakkan peralatan kapal, memecahkan segala peralatan di atas dek dan menyebabkan air memasuki kapal. Pada 7 ogos 1880, enjin kapal tidak lagi berfungsi, manakala layar bertukar ganti akibat dipecahkan angin ribut. Usaha menceduk air yang memasuki kapal dilakukan dengan kerjasama jemaah haji secara berterusan. Tindakan Kapten Clark, salah seorang pemilik kapal berkenaan mengarahkan anak kapal menurunkan bot keselamatan untuk menyelamatkan diri, akhirnya menimbulkan kemarahan jemaah haji kerana hanya sebahagian kecil penumpang yang akan dapat diselamatkan. Ketika Kapten Clark dan 20 yang lain meninggalkan kapal S. S. Jeddah menggunakan bot keselamatan, penumpang $S$. S. Jeddah yang ditinggalkan di atas kapal yang hampir karam melayarkan isyarat kecemasan 'We are sinking' di salah sebuah tiang layar dan 'Send immediate assistance' di sebuah tiang yang lain. ${ }^{40}$

Enam jam selepas bot keselamatan yang dinaiki oleh Kapten Clark dan beberapa orang penumpang yang lain ditemui, kapal wap British 
Antenor yang dalam pelayaran dari Shanghai ke London bersama 680 orang penumpang ternampak isyarat kecemasan yang dibuat oleh penumpang S. S. Jeddah. Kaptennya, John T. Bragg telah menghantar penolongnya, Randolph Campbell, bersama-sama empat orang krew menyiasat masalah yang dialami S. S. Jeddah. Campbell melaporkan bahawa enjin kapal telah rosak dan air memenuhi kapal setinggi tujuh atau lapan kaki. S. S. Jeddah pasti telah karam tanpa usaha gigih dan berterusan penumpang-penumpangnya menceduk dan membuang air di dalam kapal. Antenor yang sudah cukup muatannya telah bertindak menunda $S$. S. Jeddah selama tiga hari sehinggalah kedua-duanya berlabuh di Aden pada 11 Ogos, 1880 jam 5:15 p.m.

I called the headmen amongst the pilgrims together and organized gangs amongst the pilgrims to pump and bale the vessel. This was done, the men constantly relieving ane another, and by the evening of the nineth of August, we had gained six inches on the water, and during the following night we gained a foot on the water and continued to gain on the water thenceforward until the water was reduced to three and a half feet in the engine room and five feet in the after hold. ${ }^{41}$

Secara kebetulan, pada hari Kapten Bragg melaporkan tentang penyelamatan S. S. Jeddah, Kapten Clark mengemukakan tuntutan insuran ke atas kapal yang sama dengan melaporkan bahawa semua penumpangnya karam. Kedua-dua berita tersebut telah mengelirukan masyarakat dunia sehingga akhbar The London Times mengambil langkah berhati-hati dalam menyiarkan berita pada 12 Ogos $1880 .{ }^{42}$ Peristiwa tersebut telah menyebabkan sebuah badan siasatan diwujudkan di Aden bagi mengetahui perkara sebenar di sebalik kejadian berkenaan. ${ }^{43}$ Seramai 300 jemaah haji yang menaiki kapal S. S. Jeddah telah dibawa ke Mekah dengan menumpang kapal-kapal yang menuju ke Pelabuhan Jeddah. Kargo yang rosak dilelong di Aden berharga 307.00 Rupees dan kapal tersebut dibaik pulih kerosakannya. S. S. Jeddah memulakan pelayaran sulungnya dari Aden setelah enam minggu dibaik pulih. Pada 29 September 1880, S. S. Jeddah meneruskan pelayaran ke Pelabuhan Jeddah untuk menghantar baki 269 orang bakal haji. ${ }^{44}$

Peristiwa yang berlaku terhadap kapal $S$. S. Jeddah yang mencuri tumpuan masyarakat antarabangsa telah menjejaskan reputasi Kerajaan British. Joseph Conrad ${ }^{45}$ di dalam novelnya Lord Jim yang diilhamkan daripada peristiwa tersebut turut menggambarkan keadaan kapal haji S. S. Patna sebagai kecil, sesak dan terlalu uzur. ${ }^{46}$ Tekanan yang dibuat oleh pegawai-pegawai British agar perubahan dilakukan ke atas peraturan kapal dan pelayaran yang memenuhi piawaian dilakukan berkemungkinan besar didorong oleh desakan masyarakat antarabangsa, sekali gus bagi menjaga nama baik Kerajaan 
British. Tekanan tersebut nyata berbeza dengan kehendak syarikat perkapalan British yang ingin memaksimumkan jumlah penumpang bagi mengurangi kos dan bersaing dengan syarikat perkapalan negara lain. ${ }^{47}$ Keadaan kapal-kapal haji yang sangat daif dan menyedihkan adalah disebabkan oleh hasrat dan penglibatan pelbagai pihak untuk mengaut keuntungan daripada aktiviti pengerjaan haji umat Islam.

Blame for the evils of the pilgrim traffic did in fact rest on profit-seeking
businessmen of the British and Turkish empires, on Europeans and Arabs,
Christians and Moslems alike. Turkey, exporting £250,000 from Jedda in
1880 in the form of specie collected from pilgrims during their stay in the
country, exhibited as great reluctance as British colonial shipowners toward
enforcing stricter rules on the pilgrim trade, wary of reducing the flow
of the poor and their gold. It required the Jeddah scandal to expose what
had been so profitable to ignore. Ship conditions for pilgrims travelling to
Mecca improved as a result of it, while Turkish fears of income loss were
also justified: pilgrim spending fell to as low as $£ 25,000$ in $1904 .{ }^{48}$

\section{Usaha Memperbaiki Perkhidmatan Kapal Haji}

Proses menginstitusikan pengangkutan jemaah haji akhirnya menjadi kenyataan pada tahun 1886 . Beberapa tahun sebelumnya, Naib Konsul British di Jeddah, iaitu Dr. Abdur Razzack ${ }^{49}$ telah pun mencadangkan agar dipertimbangkan penubuhan sebuah agensi haji bagi mengawal selia segala urusan berkaitan haji. Cadangan beliau tidak membuahkan sebarang hasil, sehinggalah pada tahun 1881 dan 1885, apabila pihak British mengusulkan agar Syarikat Thomas Cook \& Son merangka cadangan bagi mewujudkan perjalanan yang lebih selesa dan selamat bagi jemaah haji dari India. Resolusi Kerajaan India yang dibuat pada 21 Januari 1886, telah melantik syarikat tersebut sebagai satu-satunya ejen haji di India dan beribu pejabat di Bombay. ${ }^{50}$ Syarikat tersebut bertanggungjawab sepenuhnya ke atas segala urusan pengangkutan ke pelabuhan, urusan perkapalan, penjualan tiket, pengumumam sebarang maklumat penting berkenaan urusan haji dan penubuhan pejabat haji di Bombay dan Jeddah. ${ }^{51}$ Walau bagaimanapun, sistem tersebut gagal mencapai matlamat kerana syarikat tersebut hanya menghadkan urusan menyewa kapal dan mengetepikan pemantauan ke atas keadaan kapal. Khidmat syarikat tersebut akhirnya ditamatkan pada tahun $1893 .{ }^{52}$

Sepanjang tempoh akhir abad ke-19 dan awal abad ke-20, penggubalan undang-undang yang diperkenalkan di Negeri-Negeri Selat dan Negeri-Negeri Melayu tertumpu kepada pengawalan keadaan kapal. Indian Native Passenger Ship Act pada tahun 1887, dan Ottoman Pilgrim Traffic Regulations pada tahun 1888, telah mendesak Kerajaan Negeri-Negeri Selat memastikan kawalan yang lebih ketat terhadap 
keadaan di dalam kapal. ${ }^{53}$ Merchant Shipping Ordinances 1910, Bahagian IV, Peraturan Kapal-kapal Haji memuatkan beberapa peruntukan yang mencegah penggunaan kapal-kapal tidak berjadual dan tidak dilengkapi kemudahan-kemudahan seperti tempat penyimpanan barang dan sistem pengaliran udara. Ruangan bagi setiap individu telah ditetapkan untuk setiap kapal yang membawa jemaah haji. Sijil pengesahan dikeluarkan bagi kapal-kapal haji yang telah memenuhi piawaian yang ditetapkan. ${ }^{54}$

Konvensyen Kebersihan Antarabangsa Tahun 1921 dan 1926 akhirnya telah mencetuskan pembaharuan ke atas keadaan kapalkapal haji, bersesuaian dengan cadangan awal yang diusulkan oleh Abdul Majid Zainuddin, Pegawai Haji Tanah Melayu Pertama agar mewajibkan setiap syarikat perkapalan menyediakan makanan di atas kapal-kapal haji. ${ }^{55}$ Sejak pelantikan beliau, Abdul Majid Zainuddin begitu gigih melobi agar cadangan tersebut dilaksanakan. Usaha tersebut hanya menampakkan hasil pada tahun 1927 dengan penubuhan sebuah jawatankuasa yang dipengerusikan oleh J. D. Hall. ${ }^{56}$ Jawatankuasa tersebut mempertimbangkan segala cadangan dan hujah yang dikemukakan oleh Pegawai Haji Tanah Melayu, Konsul British, Biro Perisikan Politik Negeri-Negeri Selat dan syarikat-syarikat perkapalan. ${ }^{57}$

Menjelang musim haji tahun 1929, Merchant Ships Ordinance 1929 yang mewajibkan penyediaan makanan oleh semua syarikat perkapalan yang terlibat dengan pengangkutan jemaah haji bagi menjamin kemaslahatan, kesihatan, keselamatan dan keselesaan jemaah haji telah dikuatkuasakan. ${ }^{58}$ Tindakan tersebut juga diambil bagi mengatasi risiko kebakaran kerana dapur kayu dan minyak tanah sering digunakan oleh jemaah haji untuk memasak. Terdapat segelintir jemaah haji yang memasak air untuk membuat kopi dan teh pada waktu lewat malam selepas waktu yang dibenarkan. ${ }^{59}$ Abdul Majid Zainuddin, sejak laporan pertamanya pada tahun 1924, mencadangkan agar jemaah haji dilarang membawa dan memasak makanan sendiri di dalam dek. Menurutnya, banyak permasalahan dapat diselesaikan sekiranya pihak kapal menyediakan makanan, seperti kesesakan di atas kapal dapat diatasi kerana jemaah haji tidak lagi perlu membawa kayu api dan peralatan memasak. Peti sahara, bungkusan baju, bekas air dan timbunan kayu api memenuhi sekurang-kurangnya separuh daripada ruangan yang diperuntukkan bagi jemaah haji. ${ }^{60}$

Walaupun pelbagai tindakan telah diambil dan denda dikenakan, kesesakan kapal masih merupakan permasalahan utama pada sekitar tahun 1920-an sehingga 1940-an. Tulisan yang dimuatkan di dalam akhbar dan makalah berbahasa Melayu sering memaparkan pandangan dan ketidakpuasan hati orang Melayu terhadap layanan yang diberikan 
kepada jemaah haji dalam urusan pengangkutan. Antara perkara yang turut dipertikaikan ialah kelebihan dan keistimewaan dalam pelayaran yang diberikan kepada para pegawai British yang kembali ke Eropah kerana bercuti atau berpencen tetapi tidak diberikan kepada jemaah haji yang membayar hasil negeri seumur hidup. Pengabaian terhadap keselesaan jemaah haji dalam pelayaran disifatkan sebagai penghinaan terhadap maruah agama dan bangsa. ${ }^{61}$ Rencana Pengarang akhbar Saudara yang diterbitkan pada tahun 1936, umpamanya menyuarakan desakan agar pihak berkuasa mengambil tindakan segera terhadap masalah berkenaan:

Kita telah pergi melawat kapal tersebut [Cyclops] maka pemandangan dan perhatian kita atas kedahsyatan keadaan saudara ${ }^{2}$ kita yang di dalam kapal itu telah memaksa kita menulis sekali lagi berseru kepada yang berkuasa di dalam masalah pelayaran orang ${ }^{2}$ haji ini dengan pengharapan mudah²an dapat dengannya dibangkitkan perasaan insaf dan kasihan belas yang sedang mendak di dalam sanubari mereka yang berkuasa lagi bermuslihat di dalam pengelolaan perkara pelayaran orang $^{2}$ haji itu... sesiapa pun daripada kita yang berperasaan kemanusiaan kelak mempersetujukan kata kita bahawa keadaan dan peraturan yang disediakan di dalam kapal itu kerana tumpangan orang ${ }^{2}$ haji itu tidak berapa jauh bezanya dengan keadaan persediaan kerana membawa sekawan...Sedih hati hendak menyebutnya...maka patutkah kita berpeluk tubuh mendiamkan diri kita atas keadaan yang menyakiti beribu-ribu orang daripada saudara ${ }^{2}$ kita setiap tahun? ${ }^{62}$

Walau bagaimanapun, kepatuhan terhadap peraturan yang digariskan di dalam Konvensyen 1926, terutamanya berhubung kesesakan dan kebersihan kapal haji dapat dilihat secara beransur-ansur sejak tahun 1934 bagi pelayaran dari Pelabuhan Singapura ke Jeddah berbanding pelayaran sebaliknya dari Jeddah ke Singapura. Keadaan tersebut disebabkan penguatkuasaan yang lebih tegas di Pelabuhan Singapura telah digerakkan oleh Biro Perisikan Politik Negeri-Negeri Selat, sedangkan pemantauan di Jeddah hanya terbeban di bahu Pegawai Haji Tanah Melayu seorang yang sememangnya telah mempunyai tanggungjawab yang banyak..$^{63}$

Antara tahun 1935 sehingga 1945, tumpuan tidak lagi diberikan terhadap isu kebersihan dan kesesakan kapal, sebaliknya lebih kepada menaikkan taraf kemudahan penumpang dan peralatan keselamatan di atas kapal. Beberapa peraturan yang digubal dalam tahun 1939 di bawah Merchant Shipping Ordinance telah memperuntukkan pindaan terhadap peralatan pencegahan kebakaran dan penyelamatan nyawa. Ordinan 221940 telah mengukuhkan lagi peruntukan yang dibuat 
tahun sebelumnya, terutama berkenaan pemeriksaan kapal haji dan pengeluaran sijil bagi kapal-kapal yang mematuhi piawaian dari aspek kesihatan, peralatan keselamatan, sistem pengaliran udara dan peruntukan ruangan yang mencukupi bagi penumpang. ${ }^{64}$

\section{Kesimpulan}

Ternyata pelayaran ke Tanah Suci bagi menyempurnakan rukun Islam kelima menuntut kesabaran dan pengorbanan yang begitu tinggi. Isu kesesakan kapal haji hanya sebahagian daripada permasalahan yang sering membelenggu jemaah haji. Selain daripada isu kesesakan kapal, eksploitasi ejen haji dan pemerasan kadar tambang merupakan antara cabaran terbesar yang sering membelenggu jemaah haji Melayu. Walaupun pelbagai rungutan dan kecaman disuarakan oleh banyak pihak berhubung perkara tersebut tidak banyak perubahan yang berlaku. Sehingga tahun 1952, masih terdapat laporan tentang masalah kesesakan dan ventilasi udara yang tidak memuaskan di atas kapal haji. Permasalahan yang tidak pernah selesai dan komitmen untuk mengurangi tempoh perjalanan telah mengakibatkan permintaan terhadap kapal laut semakin merosot. Pengangkutan udara akhirnya telah mendominasi pengangkutan haji sebagai salah satu usaha pihak Lembaga Urusan dan Tabung Haji menawarkan perkhidmatan yang lebih baik kepada jemaah haji. Mulai tahun 1977, perkhidmatan kapal haji telah ditamatkan sepenuhnya memandangkan permintaan terhadapnya dalam kalangan jemaah haji semakin merosot.

\section{Nota}

1 W. R. Roff, "Sanitation and Security: The Imperial Powers and the Nineteenth Century Hajj", Arabian Studies, Vol. VI, 1982, hlm. 145.

2 Lihat Omar Farouk Shaeikh Ahmad, "The Arabs in Penang", Malaysia In History, Vol. XXI, No. 2, 1978, hlm. 1.

3 Sarnia Hayes Hoyt, Old Penang, Singapore: Oxford University Press, 1991, hlm. 83.

$4 \quad$ C. S. Hurgronje, The Achehnese, Leiden: E. J. Brill, 1906, Vol. 1l, hlm. 19.

5 Sehingga awal abad ke-20, perdagangan menggunakan kapal layar di sekitar Kepulauan Melayu dimonopoli oleh orang Arab.

6 Antara pedagang Culia yang berjaya mencipta nama di Pulau Pinang adalah Mohamed Merican Nordin Marakayar. Pada tahun 1830-an, perdagangan beliau telah berkembang pesat dan merupakan salah seorang pedagang yang berpengaruh di Pulau Pinang. Kebanyakan kapal-kapalnya terlibat dalam perdagangan transit, iaitu pertukaran kain dari India dengan lada hitam dari Aceh. Sejak tahun 1838, namanya disebut di dalam akhbar Pinang Gazette and Straits Chronicle sebagai orang yang paling banyak mengirim kargo ke India, Sumatera, Singapura, 
dan Burma. Pada tahun tersebut sahaja, sebanyak 17 buah kapal telah dihantar ke pelabuhan di Sumatera, Singapura, India, dan China. Anak ketiga beliau, Habib Merican Nordin pernah menjadi ejen beberapa kapal wap yang berulang-alik antara Pulau Pinang, Aceh, Deli, Langkat dan Sumatera Barat. Beliau juga pernah memegang jawatan Pengarah kepada Syarikat Indian Merchant and Steam Navigation. Kemungkinan besar, kapal-kapal mereka pernah digunakan untuk membawa jemaah haji sekurang-kurangnya sehingga ke India. Lihat Salina Zainol, Hubungan Perdagangan Aceh dengan Pulau Pinang, Kuala Lumpur: Penerbit Universiti Malaya, 2005, hlm. 130-131, 134-135 dan 137-138; A. Wright \& Cart Wright, Twentieth Century Impressions of British Malaya, London: Lloyd's Great Britain Publishing Company Ltd., 1908, hlm. 752 dan Helen Fujimoto, South Indian Muslim Community and the Evolution of the Jawi Peranakan in Penang up to 1948, ILCAA, Tokyo: Tokyo Geikokugo Daigaku, 1988, hlm. 38. Lihat juga Pinang Gazette and Straits Chronicle, 12 Mei 1838; 17 Februari 1838; 20 Oktober 1838 dan 24 November 1838. John Anderson, Acheen and the Ports on the North and East Coasts of Sumatra, Kuala Lumpur: Oxford University Press, 1971, hlm. 164 dan Salina Zainol, Hubungan Perdagangan, hlm. 76-77.

C. S. Hurgronje, Mecca In The Latter Part of the Nineteenth Century, Leiden: E. J. Brill, hlm. 217-218.

9 Biro Perjalanan Haji di Indonesia Masa Kolonial:Agen Herklots dan Firma Alsegoff \& Co, Jakarta: Arsip Nasional Republik Indonesia, 2001, hlm. $x$ dan Martin van Bruinessen, "Mencari Ilmu dan Pahala di Tanah Suci Orang Nusantara Naik Haji”, dalam Dick Douwes dan Nico Kaptein, (ed.) Indonesia dan Haji, Jakarta: INIS, 1997, hlm. 127.

10 J. C. van Leur, Indonesian Trade and Society Essays in Asian Social and Economic History, The Hague: W. Van Hoeve Publishers Ltd., 1967, hlm. 86-87.

11 Mohammad Redzuan Othman, "Menyahut Panggilan Kaabah: Sejarah Pemergian Orang Melayu ke Tanah Suci dan Kepentingannya Kepada Orang Melayu Sebelum Perang Dunia Kedua", Jurnal Usuluddin, Bil. 18, Disember 2003, hlm. 188 dan Md. Sidin dan Mohammad Redzuan, The Malays in The Middle East, Kuala Lumpur: University Malaya Press, 2000, hlm. 18.

12 C. M. Turnbull, A History of Singapore 1819-1988, Singapore: Oxford University Press, Second Edition, 1989, hlm. 64 dan 91.

13 Eldon Rutter, "The Muslim Pilgrimage", Geographical Journal, Vol. LXXIV, No. 3, 1929 hlm. 271 dan Muhammad Redzuan, "Menyahut Panggilan Kaabah", hlm. 194.

14 Nabihah bt. Hj. Hasan, Sejarah Pengerjaan Haji Orang-orang Tanah Melayu, 1900-1940, Latihan Ilmiah Ijazah Sarjana Muda,Universiti Kebangsaan Malaysia, 1978, hlm. 90.

15 Pemilik syarikat berkenaan adalah Haji Mohd. Hassan Namazie dan agennya di Singapura adalah anak saudara beliau sendiri, Mohd. Ali Namazie, J. P. Abdul Majid Zainuddin, Pegawai Haji Tanah Melayu Pertama telah menggunakan perkhidmatan kapal syarikat tersebut 
dalam pelayaran pergi balik di antara Singapura-Jeddah pada tahun 1923. Namun begitu, pelayaran tersebut tidak menyenangkan kerana memakan masa yang terlalu lama, iaitu 22 hari berbanding hanya 15 hari bagi kapal Blue Funnel. Beliau memilih kapal syarikat tersebut kerana kemudahan makanan yang disediakan bagi jemaah haji di atas kapal. Namun begitu, tanggapan beliau ternyata meleset apabila makanan berkenaan hanya diperuntukkan bagi jemaah haji Jawa dari Hindia Belanda. Beliau bernasib baik kerana diberi bekalan makanan oleh orang yang bertanggungjawab menyediakan makanan bagi jemaah haji Jawa. Lihat Abdul Majid Zainuddin, The Wandering Thoughts of A Dying Man, W. R. Roff (ed.), Kuala Lumpur: Oxford University Press, 1978, hlm. 148-149 nota 69.

16 Dua buah kapal syarikat tersebut yang pernah digunakan membawa jemaah haji Tanah Melayu ialah Lok Sun dan Ling Nam. Lihat FO 371/12248, "Report on the Hajj of 1345AH (1927)", dan "Report on the Hajj of 1346AH (1928)", dalam RoTH, Vol. 6, hlm. 143-144 dan 205.

Lihat "Report on the Hajj of 1342AH (1924)", FO 371/10812 dalam RoTH, Vol. 5, hlm. 586-587; “Report on the Hajj of 1344AH (1926)", FO 371/11436 dalam RoTH, Vol. 6, hlm. 43, 45 dan 60-61 dan "Report on the Hajj of 1345AH (1927)", FO 371/12248 dalam RoTH, Vol. 6, hlm. 144. Lihat juga "The Pilgrims and Pilgrim Ships Enactment", No. 7, 1930, Seksyen 219 (1c) dan "Pilgrims Ordinance", 195, Seksyen 34 (1c).

Kassim Ahmad, (ed.), "Kisah Pelayaran Abdullah ka-Judah", dalam Kisah Pelayaran Abdullah ka-Kelantan dan ka-Judah, Kuala Lumpur: Oxford University Press, 1960, hlm. 142-143.

Pengalaman perit yang dilalui oleh jemaah haji turut dilaporkan di dalam akhbar harian Indonesia Java Bode tahun 1924, "Orang-orang benar-benar berdesakan di dalam palkah kapal tanpa lampu penerangan dan udara segar, sehingga keadaan betul-betul tidak dapat dipertahankan dalam iklim tropis. Keadaan menyedihkan dalam soal kesehatan dan...soal moral di kapal yang mengangkut jemaah haji, maka dapat dibayangkan gambaran yang mengerikan, jika orang berpikir bahwa di antara jemaah haji ada wanita-wanita hamil, yang melahirkan bayinya dalam ruangan kapal yang penuh sesak...dan banyak anak-anak kecil". Lihat Kees van Dijk, "Perjalanan Jemaah Haji Indonesia", dalam Dick Douwes dan Nico Kaptein, (ed.), Indonesia dan Haji, hlm. 84.

20 Jaafar bin Jusoh, Perihal Pemergian ke Mekah dan Madinah, iaitu Pelayaran dan Perjalanan Ke Mekah al-Mushrifah Bagi Mengerjakan Haji dan ke Madinah al-Munawwarah Bagi Ziarah Makam Rasulullah s.a.w. dan Sahabat-sahabatnya, Johor Bharu: Soo Ping Hang Press, 1937, hlm 39-40.

21 Untuk maklumat lanjut mengenai isu kesesakan kapal haji lihat "Overcrowding of Pilgrims Ships to Jeddah", 9 Julai 1869, CO 273/30/8370; "Overcrowding of Pilgrim Ships from Singapore", 11 Julai 1873, CO 273/67/8938; "Overcrowding of Pilgrims Ships at Singapore", 9 April 1873, CO 273/73/3405; “Overcrowding of Pilgrim Ships", 29 September 1873, CO 273/73; “Overcrowding of Pilgrim Ships from Singapore to 
Jeddah", 12 May 1874, CO 273/75/4001 dan "Overcrowding of Pilgrim Ships", 14 November 1873, CO 273/72/12121.

S. Baring-Gould \& C. A. Bampfylde, A History of Sarawak under its Two White Rajahs, 1839-1908, London: Henry Sotheran \& Co., 1909, hlm. 443444.

W. R. Roff, "Sanitation and Security: The Imperial Powers and the Nineteenth Century Hajj", Arabian Studies, Vol. VI., 1982, hlm. 145. J. M. Gullick, Malay Society in the Late Nineteenth Century The Beginning of Change, Singapore: Oxford University Press, 1987, hlm. 298. Lihat juga Mary Byrne McDonnell, The Conduct of Hajj From Malaysia and Its Socio-Economic Impact on Malay Society: A Descriptive and Analytical Study, 1860-1981, Phd Dissertation, Columbia University, 1986, hlm. 62; Mohammad Redzuan Othman, "Menyahut Panggilan Kaabah: Sejarah Pemergian Orang Melayu ke Tanah Suci dan Kepentingannya Kepada Orang Melayu Sebelum Perang Dunia Kedua", Jurnal Usuluddin, Bil. 18., 2003, hlm. 188-190 dan Md. Sidin Ahmad Ishak dan Mohammad Redzuan Othman, The Malays in the Middle East, Kuala Lumpur: Oxford University Press, Second Edition, 1989, hlm. 10 dan 18.

Lihat "Alleged Overcrowding of Pilgrim Ships at Singapore", 4 Julai 1873, CO 273/67/8938. Bahan ini mengemukakan senarai kapal dan jumlah penumpang yang meninggalkan pelabuhan Singapura pada tahun 1871 dan 1872. Lihat "Alleged Overcrowding of Pilgrim Ships at Singapore", 4 Julai 1873, CO 273/67/8938. Lihat "Letter from British Consulate, Jeddah to Government, Bombay", 30 April 1875, FO 78/2418 dalam Records of The Hajj (RoTH) A Documentary History of the Pilgrimage to Mecca, London: Archive International Group, Archive Edition, 1993, Vol.3, hlm. 363-367. Mary Byrne McDonnell, The Conduct Of Hajj, hlm. 61. Kapten Henry Carter (1841-?) pernah berkhidmat sebagai kapten kapal Charles Hinkey (1875), Colonel Cook (1881) dan Selkirk (1882). Beliau juga pernah bertugas sebagai jurumudi kanan di atas kapal Egyptian (1883), S. S. Rhodes (1890) dan beberapa buah kapal lagi. Jerry Allen, The Sea Years of Joseph Conrad, New York: Garden City, 1965, hlm. 126. Lihat "Letter from British Consulate, Jeddah to Government, Bombay", 30 April 1875, FO 78/2418 dalam RoTH, Vol.3, hlm. 363-367. Lihat Orfeur Cavenagh, Reminiscences of An Indian Official, London: W. H. Allen and Co., 1884, hlm. 298 dan J. M. Gullick, Malay Society, hlm. 298 dan 312 nota 132.

M. Dien Majid, Berhaji di Masa Kolonial, Jakarta: CV Sejahtera, 2008, hlm. 51-52.

34 Ibid., hlm. 365. Sistem yang telah digunakan oleh Kerajaan Peranchis dan Belanda ini telah menampakkan kejayaan besar. Setiap pasport yang disimpan di Pejabat Konsul mengandungi butir-butir peribadi yang lengkap. Lihat juga "Letter from British Consulate, Jeddah to Political 
Resident, Aden", 27 Mei 1875, FO 78/2418 dalam RoTH, Vol.3, hlm. 368375.

"Letter from British Consulate, Jeddah to Foreign Office, London", 20 Ogos 1875, FO 78/2418 dan "Letter from British Consulate, Jeddah to Political Resident, Aden", 27 Mei 1875, dalam RoTH, Vol. 3, hlm. 376-381.

Peristiwa yang menimpa kapal S. S. Jeddah digambarkan secara terperinci dalam Jerry Allen, The Sea Years of Joseph Conrad, hlm. 120-150. Kapal tersebut adalah hak milik bersama Kapten Clark dan Syed Mohammad bin Ahmad Alsagoff, salah seorang pedagang Arab terkaya yang mewarisi firma perkapalan yang mengangkut jemaah haji dari Singapura ke Jeddah. S. S. Jeddah beroperasi di bawah pengendalian Syarikat Singapore Steamship Company dan belayar di bawah bendera British. Kedua-dua pemiliknya merupakan tokoh yang sangat terkenal di Singapura waktu itu dan memiliki hubungan yang erat dengan pihak pentadbir British. Lihat Jerry Allen, The Sea Years, hlm. 126.

Mohammad Redzuan Othman, "Menyahut Panggilan Kaabah", hlm. 189; W. R. Roff, "Sanitation and Security", hlm. 151 dan Ronald McKie, Singapore, Sydney: Angus and Robertson, 1972, hlm. 136

Lihat Jerry Allen, The Sea Years, hlm. 120-122 dan 125. Rutin pelayaran kapal S. S. Jeddah selama tiga minggu adalah merentasi Lautan Hindi membawa jemaah haji Tanah Melayu dan Hindia Timur Belanda berulangalik di antara Singapura dan Jeddah.

Lihat Jerry Allen, The Sea Years, hlm. 120-122 dan 125-126. Daripada kesemua jumlah penumpang dan krew kapal, hanya tujuh daripadanya berbangsa Eropah, iaitu Kapten Clark dan isteri, William, penolong beliau, ketua jurutera, jurutera kedua dan jurutera ketiga.

Kapten Clark dalam laporan yang dibuatnya di Aden pada 10 Ogos 1880 mendakwa bahawa jemaah haji Melayu telah bertindak ganas membunuh penolong kepada William dan jurutera kedua. Mereka yang cuba menyelamatkan diri dengan bot keselamatan turut dilontarkan objek-objek keras. Berita mengenai mala petaka yang menimpa jemaah haji tersebut telah mendapat liputan dunia, terutamanya di London, Singapura, dan Madras. Kesemua 21 orang penumpang bot berkenaan telah diselamatkan dan dibawa ke Aden oleh kapal wap dari Liverpool, iaitu Scindia yang dalam pelayaran dari Pelabuhan Akyab, Burma. Lihat Jerry Allen, The Sea Years, hlm. 134.

41 Jerry Allen, The Sea Years, hlm. 135-136. Aden merupakan pelabuhan terhampir dengan tempat kejadian. John T. Bragg dan Randolph Campbell terpaksa berhadapan dengan pilihan yang amat sukar, iaitu membahayakan nyawa 680 orang penumpangnya, kargo bernilai $£ 84,000$ dan kapal berharga $£ 30,000$ atau membiarkan sahaja 1,000 nyawa bakal haji karam di laut.

42 Jerry Allen, The Sea Years, hlm. 136 dan 137. Laporan yang dibuat oleh The London Times adalah bercanggah di antara 10 dan 11 Ogos 1880. ADEN: AUGUST, 10, The Steamer JEDDAH of Singapore bound for Jeddah, with 953 pilgrims on board, foundered off Cape Guardafui on the eight inst. All on board perished, excepting the Captain, his wife, the chief officer, the chief engineer, the 
assistant engineer, and sixteenth natives. The survivors were picked up by the steamer SCINDIA and landed here. ADEN: August, 11, 7.50 P.M., The Jeddah, which was abandoned at sea with 953 pilgrims on board, did not founder, as reported by the master. She has just arrived here, all safe, in tow of the steamer ANTENOR.

Untuk laporan terperinci badan siasatan berhubung kes S. S. Jeddah, lihat "Report of a Court of Inquiry held at Aden into the cause of the abandonment of the steamship "Jeddah", http://www.plimsoll.org/ images/14642_tcm4-165526.pdf.

Jerry Allen, The Sea Years, hlm. 141 dan 145. Peristiwa tersebut memberikan tamparan hebat kepada pemilik S. S. Jeddah. Keengganan masyarakat menggunakan perkhidmatan kapal yang mempunyai reputasi buruk menyebabkan Syarikat Singapore Steamship Company terpaksa menghentikan perkhidmatan pengangkutan haji empat setengah tahun selepas peristiwa hitam tersebut. Pada 24 Februari 1885, S. S. Jeddah telah dijual kepada Inche Yayah bin Sheban dari Johor. Pada tahun 1886, kapal tersebut telah menjadi milik Lee Phee Yaow dari Pulau Pinang dan ditukar namanya kepada S. S. Diamond bagi memadamkan ingatan masyarakat terhadap peristiwa hitam yang pernah dialaminya. Lihat juga Ronald McKie, Singapore, Sydney: Angus and Robertson, 1972, hlm. 136. Joseph Conrad adalah seorang penulis yang tidak asing lagi di Singapura dan banyak menulis kisah-kisah perkapalan. Nama asal beliau ialah Józef Teodor Konrad Korzeniowski. Beliau tiba di Singapura pada tahun 1882 dan pernah menjadi ketua pegawai bagi kapal S. S. Jeddah. Ketika berada selama enam minggu di Rumah Kelasi yang terletak di penjuru North Bridge dan Stamford Road, beliau telah menghasilkan novelnya yang terkenal, iaitu Lord Jim. Lihat Ronald McKie, Singapore, hlm. 137. Lihat Joseph Conrad, Lord Jim, London: J. M. Dent \& Sons Ltd., 1935, hlm. 10-11; Jerry Allen, The Sea Years, hlm. xi dan 114 dan W. R. Roff, "Sanitation and Security", hlm. 151. Mary Byrne McDonnell, “The Conduct of Hajj”, hlm. 62.

48 Lihat Jerry Allen, The Sea Years, hlm. 149.

49 Abdur Razzack merupakan pembantu pakar bedah dari perkhidmatan kesihatan Bengal. Pada musim haji tahun 1878, beliau dihantar menunaikan fardu haji ke Tanah Suci Mekah, sekali gus meninjau keadaan kesihatan umum, berikutan penyebaran wabak penyakit yang serius dalam kalangan jemaah haji. Dalam tahun 1882, beliau dilantik sebagai Naib Konsul British di Jeddah. Lihat W. R. Roff, "The Conduct of Hajj From Malaya and The First Malay Pilgrimage Officer", SARI, No. 1, 1975., hlm. 82.

"Letter from Government of India to Managing Partner, Thomas Cook \& Son, 21 Januari 1886, encls. Text of Resolution Regarding Pilgrims", FO 78/4094 dalam RoTH, Vol. 3, hlm. 606-612.

51 "Proposed Conditions under which Thomas Cook \& Son would be prepared to undertake the Agency and Control of the Movements of Pilgrims from India to Jeddah and back", FO 78/4094 dalam RoTH, Vol.3, hlm. 603. 
52 W. R. Roff, "Sanitation and Security", hlm. 152.

53 Ibid., hlm. 152. Lihat juga "Merchant Shipping Ordinances 1910", Part IV, Pilgrim Ships, dalam Laws of the Straits Settlements, Vol. II, 1941. SS Ordinance 125.

54 Mary Byrne McDonnell, The Conduct of Hajj, hlm. 145.

55 W. R. Roff, "The Conduct of Haij”", hlm. 89-94. Perlantikan seorang Pegawai Haji Tanah Melayu telah dicadangkan oleh Pejabat Tanah Jajahan kepada Kerajaan Negeri-Negeri Selat berpandukan sistem yang digunapakai oleh jemaah haji Syria diketuai Amir-ul-Haj. Pegawai Haji tersebut akan belayar ke Tanah Suci Mekah dengan kapal pertama setiap kali musim haji dan membuka pejabatnya di Jeddah. Semua jemaah haji Tanah Melayu diwajibkan mengemukakan tiket bagi pelayaran pulang ke pejabat tersebut sebagai langkah keselamatan. Setelah tamatnya musim haji, beliau akan membawa pulang kesemua tiket yang tidak digunakan dan harta peninggalan jemaah haji yang meninggal dunia. Abdul Majid Zainuddin telah memulakan tugas mulai musim haji 1923, tetapi perlantikan rasmi sebagai Pegawai Haji Tanah Melayu Pertama bermula pada 1 Januari 1924 kerana pihak Kerajaan Negeri-Negeri Selat memerlukan waktu bagi merangka peraturan-peraturan yang berkaitan dengan tugas tersebut.

J. D. Hall yang merupakan Setiausaha Pesuruhjaya Tinggi British di Negeri-Negeri Melayu dari tahun 1927-1931 telah dilantik sebagai Pengerusi Jawatankuasa yang mengkaji tentang keperluan mewajibkan penyediaan makanan bagi jemaah haji Tanah Melayu di dalam kapal haji. "Hall Report on Compulsory Provision of Food", 12 Oktober 1927, British Adviser Kelantan, K1577/27. Dalam laporannya, Hall menekankan Seksyen 203(i), "Merchant Shipping Act" dan perkara 21, "Pilgrim Ships Rules", 1911, yang mensyaratkan penyediaan makanan oleh syarikatsyarikat kapal, melainkan jemaah haji membuktikan pemilikan makanan yang mencukupi. Turut disyorkan, penyediaan makanan dua kali sehari, perkhidmatan kantin untuk jualan makanan dan minuman dalam tin dan penyediaan air panas untuk membuat teh dan kopi. Dalam tahun 1928, Straits-Hejaz Company, sebuah syarikat baru dalam perniagaan pengangkutan haji telah menawarkan penyediaan makanan dengan bayaran tambahan. 90 peratus daripada penumpangnya telah bersetuju dengan tawaran tersebut. Lihat juga Mary Byrne McDonnell, "The Conduct of Hajj", hlm. 237 dan 278 nota 47.

58 Perbincangan lanjut mengenai peruntukan penyediaan makanan boleh dilihat di dalam British "High Commissioner Office to Messrs. Sime Darby \& Co. and Messrs. Mansfield \& Co. Ltd., Singapore", 30 Ogos 1929 dan "Governor of the Straits Settlements to Lord Passfield of Colonial Office", 11 Julai 1929, British Adviser Kelantan, K714/1929; "Report Compiled by Hj. Abdul Majid, The Malay Pilgrimage Officer on The Pilgrimage 1924", British Adviser Kelantan, K1039/24.

$59 \quad$ Kejadian kebakaran kapal laut di Laut Merah pernah berlaku ke atas kapal Frangestan milik Syarikat Nemazie yang membawa lebih 1,200 orang penumpang dalam tahun 1924. Kapal S. S. Rhesus yang membawa 
jemaah-jemaah haji Tanah Melayu pernah terbakar ketika berada di perairan Ceylon pada tahun 1948. Walau bagaimanapun, kerjasama yang diberikan oleh jemaah haji berjaya memadamkan kebakaran yang berlaku. Pada tahun 1976, dua buah kapal, iaitu Patra dan Mecca yang membawa jemaah haji dari Mesir dan Sudan telah terbakar dan tenggelam di Laut Merah. Lihat "Extracts from Jeddah Reports, 30 March-30 April, 1924", FO 371/10006 dalam RoTH, Vol. 5, hlm. 527; "Report of the Civil Administrator and Director, Kamaran Station on the Pilgrimage Season 1948", SUK Kelantan K1410/1949; Nabihah Hj. Hasan, "Sejarah Pengerjaan Haji", hlm. 93-95 dan Berita Minggu, 26 Disember 1976. Mary Byrne McDonnell, "The Conduct of Hajj", hlm. 224 dan "Cabutan daripada Laporan Konsul British, Jeddah", SUK Johor 1322/28.

61 Muhammad Rafiqi, "Pelayaran ke Makkah al-Mashrafa", Jasa, Thn. 3, Bil. 8, Mei 1930, hlm. 208.

62 Sayyid Sheikh al-Hadi, "Kapal Haji dan Kesengsaraan Penumpangpenumpang di dalamnya terhadap kepada yang berkuasa", Saudara, 11 November 1936, hlm. 1.

63 Mary Byrne McDonnell, The Conduct of Hajj, hlm. 238

64 Ibid., hlm. 318. 